The Spectrum of

Advanced Heat Transfer Technologies Increase Vehicle Performance and Reliability

Clean Energy Innovation

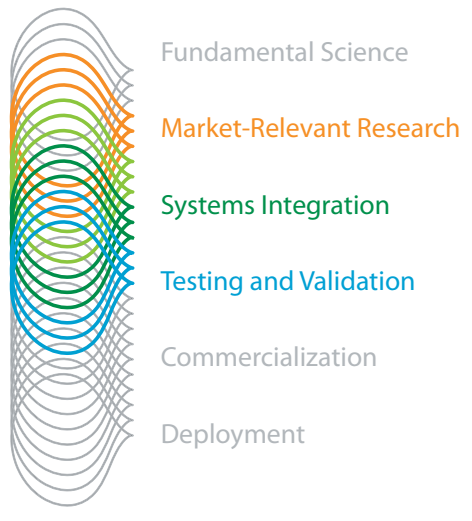

Keeping yourself cool while driving your car on a hot, sunny day can be a challenge. But it can be even more challenging to cool the power electronic components that are critically important in hybrid electric and all-electric vehicles. Researchers at the National Renewable Energy Laboratory (NREL) investigate and develop these vehicles and their components to help reduce our use of imported petroleum and curb the emissions associated with climate change.

A vehicle's power electronic components include the motor controller, converters, and inverters that condition the flow of electrical power between the battery and the electric motor. The problem is that power electronics generate a lot of heat. This heat can decrease their performance and reliability, as well as that of other vehicle components, and lead to costly component failures.

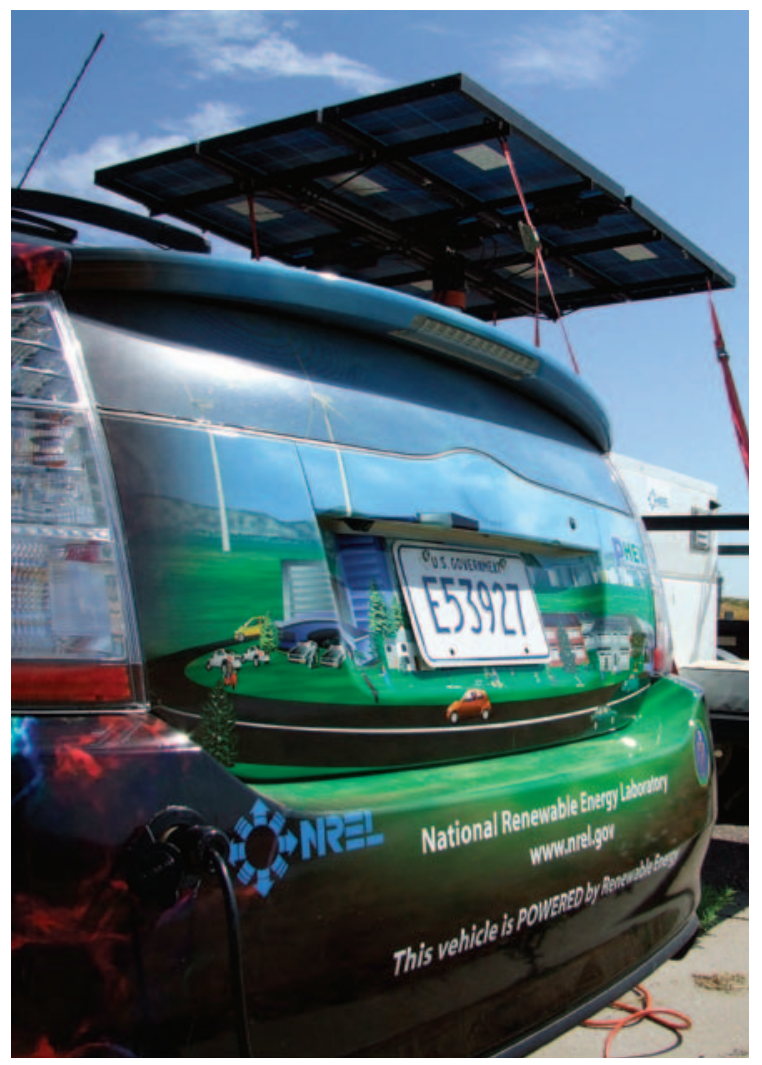

NREL modified a standard hybrid electric vehicle to a plug-in hybrid electric vehicle for demonstration and testing. This test vehicle's battery is being recharged by a photovoltaic system on NREL's campus. Tomorrow's plug-in hybrids will depend heavily on advanced batteries and reliable, cost-effective power electronics components. PIX 15137
Through deep technical expertise and an unmatched breadth of capabilities, NREL leads an integrated approach across the spectrum of renewable energy innovation. From scientific discovery to accelerating market deployment, NREL works in partnership with private industry to drive the transformation of our nation's energy systems.

This case study illustrates NREL's contributions in Market-Relevant Research through Testing and Validation.

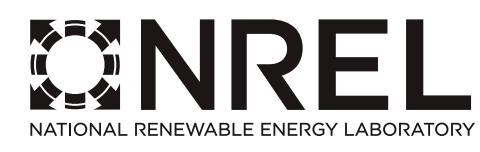

NREL is a national laboratory of the U.S. Department of Energy, Office of Energy Efficiency and Renewable Energy, operated by the Alliance for Sustainable Energy, LLC. 
That's why NREL is working with industry to develop and demonstrate advanced heat transfer technologies such as jet impingement cooling, which NREL has patented. Jet impingement cooling aims to drive down the overall cost of hybrid and all-electric vehicles by making the power electronics module more compact, by requiring fewer electronic devices, and by using less expensive materials that work just as well as more costly counterparts.

\section{How It Works}

NREL's researchers developed a patented heat exchanger that directs liquid cooling to the underside of electronic power devices attached to a copper-bonded ceramic surface. This approach eliminates the need for thermal grease and significantly enhances direct heat transfer from the electronics.

A series of nozzles is used to direct jets of liquid coolant to the copper-bonded layer. The NREL researchers drew on test results from jet nozzle experiments and used computational fluid dynamics to design their patented jet-impingement device. Those design improvements reduce thermal resistance by 35\% and achieve a more uniform temperature distribution across the electronic devices, without increasing the pressure drop required for the coolant to circulate.

\section{What Comes Next}

The NREL team worked with engineers from Semikron, a manufacturer of power electronics, to apply and demonstrate a jet-impingement cooling system integrated with a commercially available power electronics module.

Semikron supplied the hardware and feedback on the technology, and NREL supplied the engineering for the demonstration unit. The next step is to transfer the technology to industry so that an optimized power module can be developed that takes full advantage of this cooling technology.

Successful interactions with industry are hallmarks of NREL's research and development in advanced vehicles and fuels. By working with industry, university, and government partners, NREL continues to move advanced vehicle and fuel technologies into the marketplace and the U.S. economy to reduce both the costs and environmental emissions associated with the transportation sector.

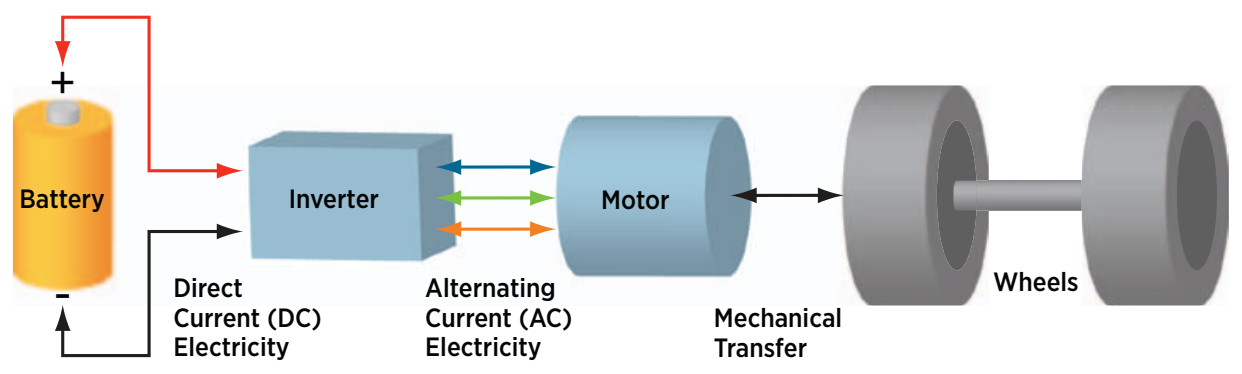

Electric, hybrid-electric, and plug-in hybrid electric vehicles rely on power electronics and electrical motors that allow the vehicle to use energy from the battery to help propel the vehicle, either alone or in combination with an engine. Basically, an inverter takes direct current electricity from the battery, converts it to alternating current, and sends the AC current to the motor. The electric motor uses the AC current to create torque to power the wheels. The motor can also act as a generator that recharges the batteries while helping the vehicle slow down. (Source: U.S. Department of Energy, Energy Efficiency and Renewable Energy, Vehicle Technologies Program)

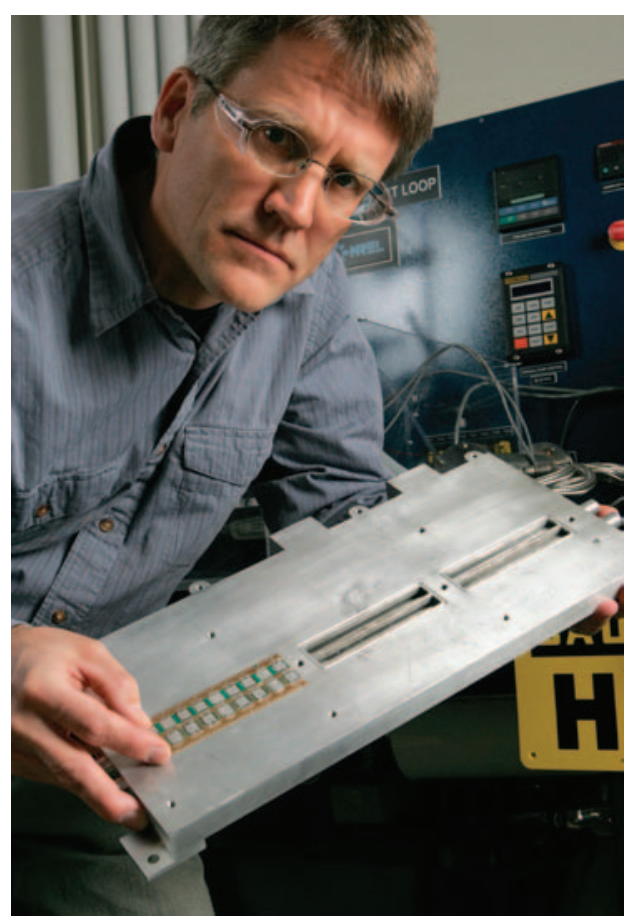

NREL researcher Ken Kelly holds a prototype cooling plate with built-in channels for liquid cooling of power electronics for the Semikron inverter. PIX 16916

\section{National Renewable Energy Laboratory}

1617 Cole Boulevard

Golden, Colorado 80401-3305

303-275-3000 • www.nrel.gov

NREL is a national laboratory of the U.S. Department of Energy, Office of Energy Efficiency and Renewable Energy, operated by the Alliance for Sustainable Energy, LLC.

NREL/FS-6A4-47574 • June 2010

Printed with a renewable-source ink on paper containing at least $50 \%$ wastepaper, including $10 \%$ post consumer waste. 